\title{
Opportunities and Challenges of Artificial Intelligence in Banking: Systematic Literature Review
}

\author{
Ahmad Ghandour \\ College of Business, Al Ain University, Abu Dhabi, UAE
}

\begin{abstract}
The primary aim of this systematic literature review (SLR) was to identify, assess and synthesize the extant evidence about the opportunities and challenges concerning the use of Artificial Intelligence (AI) in the banking sector. From the SLR, it is evident that AI has several opportunities for the sector. There are many fin-tech start-ups that offer banking AI solutions, and banking regulators are fostering AI adoption through legislation and collaboration. Other opportunities include the following: personalized services, smart wallets, decision-making and problem-solving, customer satisfaction and loyalty, process automation (especially targeting repetitive tasks), transactional security and cybersecurity improvements, and promotion of digital financial inclusion. Nevertheless, the key banking industry stakeholders have to formulate appropriate strategies aimed at overcoming existing and prospect AI challenges. Among the AI challenges that should be prioritized we include the following: job loss and user acceptance concerns, privacy breaches, creativity and adaptability loss, restrictive implementation and operational requirements, digital divide, availability of vast quality data, AI-business strategy alignment, and loss of emotional "human touch".

However, existing studies are largely descriptive and based on secondary sources of data. This necessitates empirical studies to expand the existing body of
\end{abstract}

DOI: 10.18421/TEM104-12

https://doi.org/10.18421/TEM104-12

Corresponding author: Ahmad Ghandour, College of Business, Al Ain University, Abu Dhabi, UAE. Email: ahmad.ghandour@aau.ac.ae

Received: 09 June 2021.

Revised: 19 September 2021.

Accepted: 25 September 2021.

Published: 26 November 2021.

(c))BY-NC-ND (C) 2021 Ahmad Ghandour; published by UIKTEN. This work is licensed under the Creative Commons Attribution-NonCommercial-NoDerivs 4.0 License.

The article is published with Open Access at www.temjournal.com knowledge regarding AI opportunities and challenges in the banking industry.

Keywords - Artificial Intelligence, Banking, Fintech, opportunities, challenges.

\section{Introduction}

The banking industry has become the major adopter of artificial intelligence (AI) technology. The penetration of AI technology in this industry has especially increased with the advent of Internet or online banking and self-service branch networks. Natural language processing (NLP) and machine learning systems are being used to automatically and reliably respond to customer queries, monitor saving and spending trends, and make disbursements on behalf of customers among other use cases [1], [2]. Automation of repetitive processes and tasks could save costs, minimize human error, and allow staff to focus their energy on more value-adding operations [3]. Banks are also increasingly leveraging big data analytics systems powered by AI and machine learning to offer quicker and personalized customer services and experiences. With customers being the major driver of any service industry, AI may be used to gain a greater understanding of the needs and behaviors of customers [2]. Consequently, banks leverage the increased understanding of consumers in order to personalize their products and services.

Other than customer-facing banking applications, big data analytics systems may be used to enable banking executives and managers to make more informed decisions concerning various internal business processes, operations, investments, risks, resource utilization, and so on [2]. Other compelling use cases of big data analytics and machine learning include facilitating the detection of fraudulent transactions, improving internal policy and legal or regulatory compliance, offering secure transactions, and predicting future outcomes [2], [4]. Therefore, AI technology is adequately mature to be deployed in the banking sector. Banks are harnessing it to streamline business processes, optimize service efficiency, enhance customer experiences, build strong customer relationships, foster business growth and competitiveness, and quickly respond to internal and external changes.

However, banks' adoption of AI systems comes with a number of challenges. Generally, AI-based 
systems are widely recognized as a real threat to societies. Massive implementation of AI systems in the banking sector implies increased automation of various tasks. Consequently, employees who stand to be affected by task reassignments and employment termination may react with hostility and resign. Alternatively, affected employees could become dissatisfied and inefficient [5]. Moreover, advances in neural networks and deep learning tools have made AI-based systems to be better than human decision-makers. Nevertheless, AI systems often do not demonstrate how they generate their conclusions [6]. Consequently, banking executives and managers may be exposed to costly biases in their decisionmaking. Moreover, people with the right AI competence would need to be hired to tackle potentially hidden biases in the course of data analysis and decision-making processes.

Moreover, extensive automation of customerfacing processes and subsequent reduction of customer contact could erode the emotional "human touch". Consequently, customer trust, satisfaction and loyalty may be badly ruined [7], [8]. In addition, customer loyalty could be adversely affected because of potential digital divide. The socio-economically deprived customers may not embrace AI-based systems and associated banking services [6]. Therefore, banks have to ensure that the needs, perceptions, motivations, and limitations of various groups of customers are adequately considered prior to the implementation of AI-based systems. It would be important for banks to strike the right balance between AI-based automation and the emotional value derived from customer contact.

Use of big data analytics, machine learning and predictive analytics among other AI technologies that come with AI could lead to serious data privacy breaches if proper data protection measures are not taken. This is mainly because such technologies often leverage vast volumes of data to deliver meaningful and reliable insights (Mhlanga, 2020). In most cases, privacy violations result in costly legal liabilities, reputational damages, loss of market share, and challenged business continuity [9]. Therefore, banks have to implement proper information security and privacy protection measures as they amass and analyze large datasets about customers.

This research is focused on answering the following question: What are the opportunities and challenges with regard to the use of artificial intelligence (AI) in the banking sector? Consistent with this research question, the primary aim of the systematic literature review was to identify, assess and synthesize the extant evidence about the opportunities and challenges concerning the use of AI in the banking sector. Overall, this paper intends to provide a thorough representation of $\mathrm{AI}$ in the banking sector. It is organized into five sections. In section 1a thorough background have been discussed.
In section 2 , the methodological gestalt is explained. In section 3 the results of the systematic review are presented in which it is then discussed in relation to previous studies in section 4. Finally, section 5 concludes the study.

\section{Methods}

\subsection{Search Procedures}

In total, five scholarly databases were searched to retrieve journal articles relevant to the opportunities and challenges related to the use of AI in the banking sector. The chosen databases include the following: Scopus, Google Scholar, ProQuest, EBSCOhost, and Springer. A well-structured search strategy was developed to facilitate the retrieval of the most relevant articles from these databases. The words "AND" and "OR" were used as part of Boolean logic to narrow and broaden the search accordingly. In particular, the following two search strings were used:

- (opportunities OR benefits AND challenges AND artificial intelligence AND banking OR banks); and

- (opportunities OR benefits AND risks OR threats AND artificial intelligence AND banking OR banks).

\subsection{Eligibility Criteria}

To be included in the review, the following rules were applied:

- The source needed to be a scholarly journal based on a qualitative methodological approach to support a meta-synthesis review of relevant literature. Therefore, grey literature and books were excluded from the review.

- The study needed to focus on either the opportunities or challenges related to the use of AI in the banking sector.

- The article needed to be published between 2015 and 2020 to ensure timeliness and relevance.

- The article needed to be published in English language.

\subsection{Data Extraction and Synthesis}

After identifying 14 studies that met the inclusion criteria, relevant information was extracted from those studies. A systematic thematic analysis was conducted to identify the major themes contained in each selected study. Attention was paid to the following elements: research aim and objectives, research methodology, results, practical and theoretical implications, and limitations. After extracting the items of interest, the evidence derived 
from the 14 studies was collated, summarized, organized, and compared. The obtained data was then presented in a well-structured and meaningful way to make sense of existing evidence on the research topic. Summary tables were used to document the results of the qualitative (non-metaanalysis or meta-synthesis) systematic literature review.

\subsection{Quality Criteria}

Quality assessment plays a major role in ensuring the studies that are included in a review which are consistent with the defined research goal. The scientific and/or empirical quality of selected studies should be rigorously appraised to eliminate potential biases and optimize the validity of findings [19]. As part of quality assessment, the following checklist was employed:

- Are the names of author(s) explicitly provided?

- Does the study state clear aim(s) and/or objectives?

- Does the study explicitly describes and justifies which research methods were adopted?

- Are the study findings clearly presented?

- Is the article published in an authoritative journal?

\section{Results}

\subsection{Study Flow}

After entering the search strings in into the selected scholarly databases, more than 17,100 records were yielded. Journal articles that were duplicated across more than one database were eliminated from the eventual review. The remaining articles were screened by titles, which resulted in elimination of about 17,054 straightforwardly nonrelevant studies. Further screening was done by abstract and full text, resulting in exclusion of 32 studies. The study selection exercise resulted in 14 studies that were deemed to have met the predetermined inclusion and quality criteria.

\subsection{Characteristics of Included Studies}

Table 1 summarizes the characteristics of included studies. The following elements are prioritized: authors and publication years, aim(s) and/or objectives, and research methods.

Table 1. Characteristics of included studies

\begin{tabular}{|c|c|c|c|}
\hline \# & $\begin{array}{l}\text { ss and } \\
\text { ation }\end{array}$ & Aims and/or Objectives & Research Methods \\
\hline 1 & [2] & $\begin{array}{l}\text { To explore how artificial intelligence (AI) is used in } \\
\text { the context of Indian banking industry as well as the } \\
\text { benefits and challenges facing the country's AI } \\
\text { technology. }\end{array}$ & $\begin{array}{l}\text { A descriptive study based on secondary } \\
\text { sources, including journals, reports, news } \\
\text { articles, Reserve Bank of India (RBI) portal, } \\
\text { and bank portals. }\end{array}$ \\
\hline 2 & [10] & $\begin{array}{l}\text { To study the impact of AI on India's banking sector } \\
\text { and the AI implementation challenges faced by } \\
\text { Indian banks. }\end{array}$ & $\begin{array}{l}\text { An analytical research method based on } \\
\text { secondary informational sources, including } \\
\text { journals, business magazines, and news } \\
\text { articles. }\end{array}$ \\
\hline 3 & [4] & $\begin{array}{l}\text { To identify use cases of AI in the commercial } \\
\text { banking sector and potential AI implementation } \\
\text { challenges. }\end{array}$ & A structured literature review \\
\hline 4 & [11] & $\begin{array}{l}\text { To examine the impact of } \mathrm{AI} \text { and associated } \\
\text { applications on digital financial inclusivity. }\end{array}$ & $\begin{array}{l}\text { Documentary and conceptual analysis of } \\
\text { peer-reviewed journal articles and reports. }\end{array}$ \\
\hline 5 & [8] & $\begin{array}{l}\text { To investigate the role of distance, AI, and } \\
\text { consumer behavioral biases on relationship banking }\end{array}$ & $\begin{array}{l}\text { A descriptive study based on secondary } \\
\text { materials. }\end{array}$ \\
\hline 6 & {$[12]$} & $\begin{array}{l}\text { To investigate how banks and fin-tech start-ups are } \\
\text { making AI investments and the consumer trust } \\
\text { challenges caused by AI usage. }\end{array}$ & $\begin{array}{l}\text { A case study methodological approach and } \\
\text { doctrinal sources. }\end{array}$ \\
\hline 7 & [9] & $\begin{array}{l}\text { To improve the awareness and provide further } \\
\text { direction for national policymaking and banking } \\
\text { institutions' corporate governance with respect to } \\
\text { assessing, developing, deploying, and scaling } \\
\text { complex AI algorithms. }\end{array}$ & $\begin{array}{l}\text { A descriptive study based on secondary } \\
\text { materials, especially journal articles and } \\
\text { legislative documents. }\end{array}$ \\
\hline 8 & [1] & $\begin{array}{l}\text { To investigate how the AI concept has brought } \\
\text { innovative changes in the banking sector and how it } \\
\text { affects human workers. }\end{array}$ & $\begin{array}{l}\text { An exploratory and descriptive research } \\
\text { design, which entailed surveying } 112 \\
\text { respondents drawn from a number of Indian } \\
\text { banks. }\end{array}$ \\
\hline 9 & [13] & To develop an empirical model for forecasting the & A causal-comparative study using statistical \\
\hline
\end{tabular}




\begin{tabular}{|c|c|c|c|}
\hline & & $\begin{array}{l}\text { financial failure of US national banks based on } \\
\text { information about their value investments. }\end{array}$ & $\begin{array}{l}\text { modelling and a machine learning model to } \\
\text { identify hidden patterns in historical data. }\end{array}$ \\
\hline 10 & [14] & $\begin{array}{l}\text { To analyze the evolution of } \mathrm{AI} \text { in the context of } \\
\text { Russian banks. }\end{array}$ & $\begin{array}{l}\text { A descriptive study based on secondary } \\
\text { materials }\end{array}$ \\
\hline 11 & {$[15]$} & $\begin{array}{l}\text { To develop an efficient and suitable predictive } \\
\text { model based on machine learning technique to } \\
\text { provide early warning of bank failure. }\end{array}$ & $\begin{array}{l}\text { A quantitative, meta-analysis study based } \\
\text { on data related to survived and failed Indian } \\
\text { banks between } 2002 \text { and } 2017 \text {. }\end{array}$ \\
\hline 12 & {$[16]$} & $\begin{array}{l}\text { To develop a model based on Bayesian networks } \\
\text { and artificial neural networks for intelligently } \\
\text { predicting liquidity risk in the banking sector. }\end{array}$ & $\begin{array}{l}\text { A case study research design and model } \\
\text { simulation. }\end{array}$ \\
\hline 13 & {$[17]$} & $\begin{array}{l}\text { To demonstrate how neural networks and data } \\
\text { mining techniques can facilitate knowledge } \\
\text { extraction of banking industry's databases as the } \\
\text { basis for customer churn prediction. }\end{array}$ & An empirical causal research design \\
\hline 14 & {$[18]$} & $\begin{array}{l}\text { To examine the bankruptcy of American banks, } \\
\text { considering the features specific to the Great } \\
\text { Economic Recession of } 2008 \text {. }\end{array}$ & An experimental, causal research design \\
\hline
\end{tabular}

\subsection{Synthesis of Data}

The systematic literature review (SLR) yielded evidence about the AI opportunities and challenges in the context of the banking sector. Table 2 and
Table 3 provide a summary of the SLR findings organized by the major themes evident in the selected articles. The studies adopted different terminologies to describe various AI opportunities and challenges. Therefore, the terminologies were normalized to achieve standardization and facilitate analysis

Table 2. Themes related to AI opportunities

\section{\# Themes Related to AI} Opportunities

1 Presence of many start-ups focusing on banking AI solutions

Banking regulators forcing banks to

2 adopt AI through regulation and effective collaboration

3 Personalized financial services

4 Smart wallets

Data-driven AI systems to support

5 forecasting, decision-making and problem-solving processes

6 Strong customer satisfaction and relationship

\section{Brief Description}

The fact that there are many start-ups that focus on banking AI solutions imply banks have a pool of technology firms to contract and source AI-based systems from.

Banking regulators (such as Reserve Bank of India (RBI)) are proactively pushing AI technology adoption among banks. Furthermore, central banks and FCA are collaborating with the banking sector to make AI adoption more efficient and effective.

Use of AI to analyze market trends, consumers' financial goals, personal portfolio, perceptions, and other types of information to personalize financial services.

Advanced digital wallets that support "anytime anywhere" payment transactions via personal devices, reducing reliance on physical money and promoting financial inclusion.

Personal robots, big data analytics, neural networks, machine learning, and predictive analytics are being integrated with banking information systems to deliver meaningful internal and external insights, financial plans and progress monitoring, better forecasts, and proactive risk management. For instance, expert systems and machine learning models may be used to enable commercial banks minimize lendingrelated losses by gleaning more granular insights to make more informed credit decisions. Moreover, neural networks may be used to forecast bank risk based on statistics about past bankruptcies.

As natural language processing technology matures, the issues of inconvenient physical bank visits and long queues could be eliminated through reliable smart virtual assistants and self-service chatbots that are always available. These AI technologies also mitigate the problem of human error and fatigue. Data analytics, machine learning and predictive analytics could also enhance customer understanding and targeting so that banks can tailor their products and services to specific consumer needs, preferences, perceptions,

\section{Sources}

[2], [11],

[12], [14]

[2], [11],

[12], [17]

[2], [10]

[2], [4],

[10], [11],

[13], [15],

[16], [18]

[1], [2], [4],

[8], [10],

[12], [17] 
7 Anti-money laundering and fraud detection

Automation of repetitive,

8 voluminous and time-intensive banking tasks

9 Enhanced cybersecurity, especially with respect to payment processing

10 Opportunity to promote digital financial inclusion behaviors, and motivations. Consequently, customers could become happier, more satisfied, and more loyal. AI models, machine learning algorithms, neural networks, and anomaly detection systems can be used to optimize the accuracy of anti-money laundering and fraud detection in the banking sector.

Intelligent robotic assistants may be used to automate and speed-up routine tasks. In addition, they can drive significant cost savings and employee productivity.

Through machine learning, deep learning, big data analytics, blockchain, and predictive analytics, suspicious financial activity may be proactively detected and prevented.

AI could help ensure that youths, women, low-income earners, and small businesses take part in the formal financial services market where payments, transfers, securities, credit, savings, and other services are offered to many formerly excluded persons. This is because AI plays an integral role in better financial risk control, tackling the challenge of information asymmetry, and assuring customer support.

Table 3. Themes related to AI challenges

\# Themes Related to AI Challenges

AI-driven automation

1 could result in obsolescence of some skills

2 Privacy violation concerns

3 Deprivation of creativity and adaptability

Restrictive AI

4 implementation and operational resources

5 Potential digital divide

Lack of adequate quality

6 datasets to train and test AI algorithms Integrating AI with

7 conventional banking processes

8 Loss of emotional "human touch"

\section{Brief Description}

There are concerns that AI-based banking systems could change the nature of existing jobs and make some skills obsolete, resulting in job losses. Consequently, it might be a major challenge to ensure user acceptance of AI in banks.

The capability of most banking AI systems is enabled by amassing and analyzing vast volumes of customer-related data, including demographics, expenditure patterns, physical contact, credit card and debit card details, social media profiles, and so on. In turn, the privacy and safety of consumers is at stake when using AI.

Overdependence on AI to automate decision-making and problem-solving processes could erode creativity and adaptability among employees.

The costs of implementing and operating a large-scale AI system could be extremely restrictive, especially for small banks with limited resources at their disposal. Other than the initial costs, competent data science talent would be required to sustain efficient and effective AI technology operations.

Customers who may be lacking modern personal devices (such as PCs, smartphones and tablets), Internet connectivity, and ICT skills may not be able to take advantage of banking AI systems. People of lower socioeconomic statuses may be rendered incapable to exploit banking AI.

Most AI technologies require vast volumes of structured, semi-structured and unstructured datasets, which might not be always available.

Currently, there is little evidence concerning how to effectively align AI and conventional banking processes. Consequently, it may not be possible to realize maximum value from $\mathrm{AI}$ implementation.

AI cannot wholly replace human bankers and branch networks. The roles of human bankers should be rediscovered to foster close banker-customer contact.
Sources

[1], [2], [4], [11]

[1], [2], [10]

[1], [2], [4], [11], [14]

[4], [9],

[1], [10],

[4], [10], 


\section{Discussion}

\subsection{Revisiting the Research Question}

This systematic literature review (SLR) has accomplished its goal of investigating the AI opportunities and challenges in the context of the banking sector. From sales and marketing to accounting, finance, customer service, fraud and antimoney laundering prevention, physical security, product development, and governance and compliance, AI is enabling banks to transform their business processes and operations. However, the banking sector faces a couple of challenges that may hinder the successful implementation and operation of AI technologies. These range from potential employee apathy to obsolescence of some skills, ruined creativity and adaptability, privacy breach concerns, restrictive implementation costs, and inequality.

\subsection{Discussion in Relation to Previous Research}

AI has a practically strong business case in the banking sector. Both internal and customer-facing processes can be modernized and streamlined through various AI-based systems, including robotics, natural language processing, big data analytics, machine and deep learning, neural networks, and predictive analytics among others. AI systems provide banks with opportunities to build unique capabilities for differentiating themselves from rivals. The major enabler of these capabilities is the opportunity to make smart business decision, optimize business processes, make accurate predictions, and rapidly respond to internal and external changes [3]; (Ng \& Shah, 2020).

Banks are using chatbots and robots to deliver improved customer service and pleasant experiences through 24/7 customer support [10], [12]. Furthermore, big data analytics is being used to gain a better understanding of customers as the basis for offering personalized products and services. [4] underscore the role of $\mathrm{AI}$ in reducing lending-related losses. Banks can also leverage predictive analytics, statistical models and machine learning to predict financial crisis, such as the Great Economic Recession of 2008 [13].

While AI technology raise concerns about making some skills obsolete and replacing human employees [2], [8]. [10] argue that AI stands to modernize banking processes and empower bankers to execute their day-to-day tasks better. AI-based information systems could relieve people of monotonous, timeconsuming jobs. This could lead to cost-savings. It could also allow bank employees to dedicate extra effort and time to learning and experimentations, enabling the creation of new, lucrative opportunities.
However, concerns about unemployment cannot be ignored in the wake of massive banking automation. Moreover, creativity and adaptability stand to be eroded [1], [2], [6].

Big data analytics and machine learning systems could be leveraged to quickly process vast volumes of constantly changing datasets and glean invaluable insights in a timely manner. If traditional information systems were to be used, such a feat would be practically unfeasible [5], [11]. Accelerating the insight generation process could contribute to increased business agility in terms of response to emerging issues. However, the prediction capability of AI primarily depends on the availability of vast quality datasets [11], [13]. AI could also adversely affect customer relationship management because of the lack of perceivable "human touch" in customer service [7], [8]. However, younger generations might somehow adapt to "faceless" AI systems because they are usually more tech-savvy than older persons.

In the current digital era, banks are increasingly offering AI-based mobile banking and online banking solutions to support 24/7 transactions. These solutions require the collection, analysis and storage of large business- and customer-related datasets. Machine learning tools are being used to support comprehensive and accurate analysis of these datasets, combining diverse pieces of data to glean valuable insights. In the process, the likelihood of suffering costly data leakages and privacy breaches increases [10]. Nevertheless, AI solutions (such as anomaly detection, deep learning, machine learning, and predictive analytics) are widely cited as remarkable enablers of optimized information security and privacy protection in banking [4], [20]. Nevertheless, AI-based cybersecurity implementation and maintenance could incur restrictively high costs [20]. Furthermore, with increasingly growing adoption of customer analytics and social media analytics tools, there is a need for continued collaborations between banking and regulatory agencies to improve cybersecurity and privacy protection [3].

\subsection{Limitations}

This systematic literature review (SLR) suffers from three main limitations. First, only one study out of fourteen was an original research based on primary data. The rest were descriptive studies based on secondary sources of data. Soundly, only journal articles were reviewed as part of SLR. However, all the studies were appraised to ensure that they met defined quality criteria. Lastly, an element of publication bias cannot be ruled out because the SLR only appraised and synthesized what is contained in the selected studies. 


\section{Conclusion}

AI technology has triggered a major digital disruption that has affected the entire banking sector in the 21 st century. This is primarily because AI solutions have the capacity to help banking institutions to innovate, make more informed decisions, and solve complex problems with greater levels of efficiency and effectiveness. Furthermore, predictive analytics, neural networks, machine learning, and other AI technologies can be used to enable banks make more accurate predictions and respond to emerging issues in a timely manner and appropriately. Therefore, AI is a technology that can enable banks to stay ahead of market competition. However, there are many pitfalls that have to be addressed to ensure that the opportunities fronted by AI are optimally exploited. Notable ones include privacy violation, job loss, data availability and quality, and strategic AI-business alignment concerns. While there is a wide body of knowledge that pertains to AI opportunities and challenges in the banking context, existing studies are largely descriptive and based on secondary data sources. Therefore, future studies ought to employ thorough empirical investigation techniques to deliver concrete evidence concerning AI opportunities and challenges in the banking sector.

\section{References}

[1]. Kaur, D., Sahdev, S. L., Sharma, D., \& Siddiqui, L. (2020). Banking 4.0:'The Influence of Artificial Intelligence on the Banking Industry \& How AI Is Changing the Face of Modern Day Banks'. International Journal of Management, 11(6).

[2]. Vijai, D. C. (2019). Artificial intelligence in indian banking sector: challenges and opportunities. International Journal of Advanced Research, 7(5), 1581-1587.

[3]. Boobier, T. (2020). AI and the Future of Banking. John Wiley \& Sons.

[4]. Königstorfer, F., \& Thalmann, S. (2020). Applications of Artificial Intelligence in commercial banks-A research agenda for behavioral finance. Journal of behavioral and experimental finance, 27, 100352. doi: 10.1016/j.jbef.2020.100352

[5]. Sastry, V. V. L. N. (2020). Artificial Intelligence in Financial Services and Banking Industry. Idea Publishing.

[6]. Talwar, R., Wells, S., Whittington, A., Koury, A., \& Romero, M. (2017). Beyond genuine stupidity: Ensuring AI serves humanity (Vol. 1). Fast Future Publishing Ltd.
[7]. Anshari, M., Almunawar, M.N., and Masri, M., (2019). Financial Technology and Disruptive Innovation in ASEAN. Hershey PA, USA: IGI Global.

[8]. Jakšič, M., \& Marinč, M. (2019). Relationship banking and information technology: The role of artificial intelligence and FinTech. Risk Management, 21(1), 1-18.

[9]. Caron, M. S. (2019). The transformative effect of AI on the banking industry. Banking \& Finance Law Review, 34(2), 169-214.

[10]. Kumar, S., Aishwaryalakshmi, S., and Akalya, A., (2020). Impact and Challenges of Artificial Intelligence in Banking. Journal of Information and Computational Science, 10(2) 1101-1109.

[11]. Mhlanga, D. (2020). Industry 4.0 in finance: the impact of artificial intelligence (ai) on digital financial inclusion. International Journal of Financial Studies, 8(3), 45.

[12]. Lui, A., \& Lamb, G. W. (2018). Artificial intelligence and augmented intelligence collaboration: regaining trust and confidence in the financial sector. Information \& Communications Technology Law, 27(3), 267-283.

[13]. Kasztelnik, K. (2020). Innovative Empirical Model for Predicting National Banks' Financial Failure with Artificial Intelligence Subset Data Analysis in the United States. Open Economics, 3(1), 98-111.

[14]. Goncharenko, I. A. (2019). Artificial intelligence and automation in financial services: the case of russian banking sector. Law and Economics Yearly Review, 8(1), 125-147.

[15]. Shrivastava, S., Jeyanthi, P. M., Singh, S., \& McMillan, D. (2020). Failure prediction of Indian Banks using SMOTE, Lasso regression, bagging and boosting. Cogent Economics \& Finance, 8(1).

[16]. Tavana, M., Abtahi, A. R., Di Caprio, D., \& Poortarigh, M. (2018). An Artificial Neural Network and Bayesian Network model for liquidity risk assessment in banking. Neurocomputing, 275, 25252554.

[17]. Bilal Zorić, A. (2016). Predicting customer churn in banking industry using neural networks. Interdisciplinary Description of Complex Systems: INDECS, 14(2), 116-124.

[18]. Iturriaga, F. J. L., \& Sanz, I. P. (2015). Bankruptcy visualization and prediction using neural networks: A study of US commercial banks. Expert Systems with applications, 42(6), 2857-2869.

[19]. Petticrew, M., \& Roberts, H. (2008). Systematic reviews in the social sciences: A practical guide. John Wiley \& Sons.

[20]. Soni, V. D. (2019). Role of Artificial Intelligence in Combating Cyber Threats in Banking. International Engineering Journal For Research \& Development, 4(1), 7-7. 